\title{
Inhibition of Bicarbonate Absorption by Peptide Hormones and Cyclic Adenosine Monophosphate in Rat Medullary Thick Ascending Limb
}

\author{
David W. Good \\ Renal Electrolyte Physiology Laboratory, Division of Nephrology, Departments of Internal Medicine, \\ Physiology \& Biophysics, University of Texas Medical Branch, Galveston, Texas 77550
}

\begin{abstract}
In vitro microperfusion experiments were performed to examine the effects of peptide hormones on bicarbonate and ammonium transport by the medullary thick ascending limb (MTAL) of the rat. Arginine vasopressin (AVP; $2.8 \times 10^{-10} \mathrm{M}$ in the bath) reduced bicarbonate absorption by $50 \%$ (from 7.8 to $3.7 \mathrm{pmol} / \mathrm{min}$ per $\mathrm{mm}$ ). AVP caused a similar reduction in bicarbonate absorption in tubules perfused with $10^{-4} \mathrm{M}$ furosemide to inhibit net $\mathrm{NaCl}$ absorption. Glucagon $\left(2 \times 10^{-9} \mathrm{M}\right.$ in the bath) also reduced bicarbonate absorption (from 11.7 to $7.6 \mathrm{pmol} / \mathrm{min}$ per $\mathrm{mm}$ ). The inhibition of bicarbonate absorption could be reproduced with either exogenous 8-bromocAMP or forskolin. With 8-bromo-cAMP $\left(10^{-3} \mathrm{M}\right)$ in the bath, addition of vasopressin to the bath did not significantly affect bicarbonate absorption. PTH significantly inhibited bicarbonate absorption, but the extent of inhibition was less than that observed with either AVP or glucagon. Vasopressin had no effect on net ammonium absorption in MTAL perfused and bathed with $4 \mathrm{mM} \mathrm{NH} \mathrm{NCl}_{4}$. These findings indicate that: (a) vasopressin, glucagon, and PTH directly inhibit bicarbonate absorption in the MTAL of the rat; (b) this inhibition occurs independent of effects on net $\mathrm{NaCl}$ absorption and appears to be mediated in part by cAMP; and (c) $\mathrm{HCO}_{3}^{-}$and $\mathrm{NH}_{4}^{+}$absorption can be regulated independently in the MTAL. ( $J$. Clin. Invest. 1990. 85:1006-1013.) vasopressin • cyclic AMP• thick ascending limb • renal bicarbonate transport • peptide hormones
\end{abstract}

\section{Introduction}

Medullary and cortical thick ascending limbs from rats absorb bicarbonate in vitro at rates that are comparable to rates measured in isolated, perfused cortical and medullary collecting ducts and that are sufficient to account for much of the $10-15 \%$ of filtered bicarbonate that is reabsorbed between the late proximal convoluted and early distal tubule of the rat in vivo $(1,2)$. The bicarbonate absorption occurs against both chemical and electrical gradients and is mediated predomi-

Results of these experiments were reported in part at the 20th Annual Meeting of the American Society of Nephrology (1988. Kidney Int. 33:400).

Address correspondence to Dr. David W. Good, Renal Electrolyte Physiology Laboratory, Division of Nephrology, 4.200 John Sealy Hospital, Rt. E-62, University of Texas Medical Branch, Galveston, TX 77550.

Received for publication 17 April 1989 and in revised form 3 October 1989.

J. Clin. Invest.

(C) The American Society for Clinical Investigation, Inc.

0021-9738/90/04/1006/08 $\$ 2.00$

Volume 85, April 1990, 1006-1013 nantly by apical membrane sodium-hydrogen exchange (3). In contrast to segments of the proximal tubule and collecting duct, however, little direct information is available regarding factors that control bicarbonate absorption in the mammalian thick ascending limb.

Peptide hormones such as vasopressin, glucagon (Glu), ${ }^{1}$ and PTH regulate a variety of cell functions in thick ascending limbs, including the transport of ions such as $\mathrm{Na}^{+}, \mathrm{Cl}^{+}, \mathrm{Ca}^{2+}$, and $\mathrm{K}^{+}(4-8)$. Peptide hormones also have important effects on urinary acidification, both in physiologic and pathophysiologic conditions (9-13), and recent evidence suggests that the thick ascending limb may be a site of peptide hormone action on bicarbonate transport. Micropuncture studies in rats have shown that the acute infusion of vasopressin, Glu, or PTH can alter bicarbonate reabsorption by the superficial "loop segment," the portion of the nephron between the late proximal convoluted and early distal tubule $(10,12,14,15)$. While these findings are consistent with an effect of peptide hormones on thick ascending limb bicarbonate transport, interpretation of the micropuncture experiments is complicated by the fact that the loop segment is composed of the proximal straight tubule, the thin descending limb, the thin ascending limb, and the early distal convoluted tubule, in addition to the medullary and cortical thick ascending limbs. Such heterogeneity precludes precise localization of the site(s) of hormone action. In addition, in experiments in which hormones are infused systemically, it is not possible to determine whether a change in bicarbonate absorption may be due to a direct action of the hormone on a particular nephron segment or to a change in some luminal or systemic factor that is related to the hormone and that indirectly influences bicarbonate transport. The possibility that different peptide hormones may affect different nephron segments or act via different cellular mechanisms is supported by the findings that vasopressin and Glu inhibited, whereas PTH stimulated, bicarbonate absorption in the loop segment $(10,14)$.

The purpose of the present study was to determine directly whether peptide hormones affect bicarbonate absorption in the medullary thick ascending limb of the rat. The isolated, perfused tubule technique was used so that the effects of different hormones on bicarbonate transport could be examined in the absence of changes in other systemic factors. In addition, experiments were performed to gain information regarding the signal transduction system that may be involved in the hormones' effects. Finally, because the medullary thick ascending limb also influences urinary net acid excretion by reabsorbing ammonium $(1,16-18)$, the effect of vasopressin on $\mathrm{NH}_{4}^{+}$transport also was examined. The results demonstrate that vasopressin, Glu, and PTH directly inhibit bicarbonate absorption in the rat medullary thick ascending limb, and that

1. Abbreviations used in this paper: 8-Bromo-cAMP, 8-bromoadenosine 3':5'-cyclic monophosphate; Glu, glucagon. 
the inhibition appears to be mediated in part by increased intracellular levels of cAMP. In contrast, vasopressin has no effect on net ammonium absorption, indicating that bicarbonate and ammonium transport rates can be regulated separately in this nephron segment.

\section{Methods}

Pathogen-free male Sprague-Dawley rats (Taconic Farms, Inc., Germantown, NY) weighing 60-70 g were housed in filter-top isolation cages with autoclaved food (NIH 31 diet; Ziegler Brothers, Inc., Gardners, PA) and bedding. They had free access to food and distilled water up to the time of experiments. The rats were injected intraperitoneally with $2 \mathrm{mg}$ furosemide 5-10 min before being anesthetized with sodium pentobarbitol $(50 \mathrm{mg} / \mathrm{kg}$ i.p.). The left kidney was exposed via an abdominal incision, bathed in situ for 1-2 min with ice-cold dissecting solution, and then removed and sliced for tubule dissection. As discussed previously $(1,18,19)$, these procedures help preserve the viability of rat renal tubules in vitro. Medullary thick ascending limbs were dissected at $10^{\circ} \mathrm{C}$ from the inner stripe of the outer medulla in a solution that contained (in $\mathrm{mM}$ ): $145 \mathrm{NaCl}, 2 \mathrm{~K}_{2} \mathrm{HPO}_{4}, 1.2 \mathrm{Na}_{2} \mathrm{SO}_{4}, 1$ $\mathrm{CaCl}_{2}, 1 \mathrm{Ca}$ lactate, $0.5 \mathrm{Mg}$ citrate, and 5.5 glucose. The dissection fluid was gassed with $100 \%$ oxygen and titrated to $\mathrm{pH} 7.4$.

The tubules were transferred to a temperature-controlled chamber, mounted on concentric pipettes, and perfused in vitro at $37^{\circ} \mathrm{C}$ as previously described $(1,3,18)$. Tubule fluid emerging from the distal end of the tubules was collected for timed intervals into calibrated constriction pipettes for calculation of tubule fluid flow rate and for analysis of total $\mathrm{CO}_{2}$ or total ammonia concentration. In bicarbonate transport experiments, perfusion rate averaged $1-2 \mathrm{nl} / \mathrm{min}$ per $\mathrm{mm}$; in ammonium transport experiments, a higher perfusion rate (5-6 nl/ min per $\mathrm{mm}$ ) was used to prevent development of limiting transepithelial ammonium concentration gradients (18). In all experiments the luminal perfusion solution contained (in $\mathrm{mM}$ ): $146 \mathrm{Na}^{+}, 4 \mathrm{~K}^{+}, 122$ $\mathrm{Cl}^{-}, 25 \mathrm{HCO}_{3}^{-}, 2 \mathrm{Ca}^{2+}, 1.5 \mathrm{Mg}^{2+}, 2$ phosphate, $1.2 \mathrm{SO}_{4}{ }^{2-}, 1$ citrate, 2 lactate, and 5.5 glucose. The bath solution was identical except for addition of $0.2 \%$ bovine albumin (fraction $\mathrm{V}$, essentially fatty acid free; Sigma Chemical Co., St. Louis, MO). Experimental agents were added to the bath solution as described below. In ammonium transport experiments, the perfusate and bath also contained $4 \mathrm{mM} \mathrm{NH}_{4} \mathrm{Cl}$. All solutions were equilibrated with $95 \% \mathrm{O}_{2}, 5 \% \mathrm{CO}_{2}$ and were $\mathrm{pH}$ 7.47-7.48 at $37^{\circ} \mathrm{C}$. The oxygen and $\mathrm{CO}_{2}$ tensions in the bath were maintained during the experiments by continuously flowing freshly gassed solution into the perfusion chamber as previously described $(1,18)$.

Arginine vasopressin (AVP), Glu, PTH (1-34 fragment, bovine), 8-bromoadenosine 3':5'-cyclic monophosphate (8-bromo-cAMP), and forskolin were purchased from Sigma Chemical Co. Glu was prepared as a concentrated stock solution in dilute $\mathrm{HCl}$; forskolin was prepared and stored as a stock solution $(1 \mathrm{mg} / \mathrm{ml})$ in $95 \%$ ethanol. Final ethanol concentration in forskolin bath was $0.05 \%$. An equal concentration of ethanol was added to the control bath in all forskolin experiments.

The general protocol was similar with each of the experimental agents. Tubules were equilibrated for $20-60 \mathrm{~min}$ at $37^{\circ} \mathrm{C}$ with the control bath solution ${ }^{2}$ and the perfusion reservoir was adjusted to establish a steady luminal flow rate. After equilibration, two to four tubule fluid collections were obtained for determination of control bicarbonate or ammonium transport rate (control period). The bath solution was then changed to one containing one of the experimental agents and the tubule allowed to re-equilibrate for 10-30 $\mathrm{min}$. Two to

2. After warming tubules to $37^{\circ} \mathrm{C}$, the bicarbonate absorption rate increases to a stable value over a period of $\sim 30 \mathrm{~min}$. Therefore, a 20-60-min equilibration period was allowed. The increase in bicarbonate absorption presumably reflects a change in some regulatory factor, possibly a fall in cell cAMP (see Results).
Table I. Effect of AVP on Bicarbonate Transport

\begin{tabular}{|c|c|c|c|c|c|}
\hline & \multirow[b]{2}{*}{$V$} & \multicolumn{2}{|c|}{ [Total $\mathrm{CO}_{2}$ ] } & \multirow[b]{2}{*}{$J T \mathrm{CO}_{2}$} & \multirow[b]{2}{*}{$V_{\mathrm{TE}}$} \\
\hline & & Perfused & Collected & & \\
\hline & $\begin{array}{l}\mathrm{nl} / \mathrm{min} \\
\mathrm{per} \mathrm{mm}\end{array}$ & \multicolumn{2}{|c|}{$m M$} & $\begin{array}{c}\mathrm{pmol} / \mathrm{min} \\
\mathrm{per} \mathrm{mm}\end{array}$ & $m V$ \\
\hline Control & $1.0 \pm 0.1$ & $25.9 \pm 0.2$ & $17.2 \pm 1.0^{*}$ & $7.8 \pm 0.4$ & $12.5 \pm 1.1$ \\
\hline Vasopressin & $0.9 \pm 0.1$ & $25.9 \pm 0.2$ & $21.5 \pm 0.8^{*}$ & $3.7 \pm 0.5$ & $15.1 \pm 0.7$ \\
\hline$P$ & NS & & $<0.001$ & $<0.001$ & $<0.05$ \\
\hline
\end{tabular}

Values are means \pm SE. Vasopressin was $2.8 \times 10^{-10} \mathrm{M}$ in the bath. No. of experiments $=8$ (means do not include values from three tubules in Fig. 1 studied with $\mathrm{NH}_{4} \mathrm{Cl}$ in perfusate and bath). Mean tubule length $=0.57 \pm 0.02 \mathrm{~mm}$. Total $\mathrm{CO}_{2}$ concentration in the bath was $26.8 \pm 0.4 \mathrm{mM}$ in control and $26.7 \pm 0.3 \mathrm{mM}$ with vasopressin. $V$ is fluid collection rate; $J T \mathrm{CO}_{2}$ is absolute rate of total $\mathrm{CO}_{2}$ absorption; $V_{\mathrm{TE}}$ is transepithelial voltage, oriented lumen positive with respect to bath. $P$ values compare control and vasopressin (paired $t$ test). * Collected total $\mathrm{CO}_{2}$ concentration significantly different from perfused (paired $t$ test).

seven additional tubule fluid collections were then obtained (experimental period). Finally, the agent was removed from the bath and control measurements were repeated (recovery period). Complete recovery generally was observed within $30-40 \mathrm{~min}$. In some experiments, only two periods (either control and experimental or experimental and recovery) were studied. Also, longer time periods were used with some agents (see Results).

Total carbon dioxide concentrations in perfusion and bathing solutions and in collected tubule fluid were measured by microcalorimetry as previously described $(1,3)$. Total ammonia concentrations were measured by microfluorometry (1). Transepithelial voltage was measured between calomel cells using a digital electrometer $(1,18)$. Because net fluid transport is absent in rat thick ascending limbs in both the presence and absence of vasopressin $(1,19-21)$, absolute rates of total $\mathrm{CO}_{2}$ or total ammonia absorption $\left(J_{\mathrm{i}}\right.$, picomoles/minute per millimeter) were calculated as $J_{\mathrm{i}}=V\left(C_{\mathrm{o}}-C_{1}\right) / L$, where $V$ is fluid collection rate (nanoliters/minute), $C$ is total $\mathrm{CO}_{2}$ or total ammonia concentration in perfused (o) and collected (1) fluid (millimolar), and $L$ is perfused tubule length (millimeters). ${ }^{3} \mathrm{~A}$ mean fluid collection rate, transepithelial voltage, and total $\mathrm{CO}_{2}$ or total ammonia absorption rate were calculated for each period studied in a given tubule. When control measurements were made at the beginning and end of an experiment, the control values were averaged. Single tubule values, presented in the figures, were averaged to obtain the group means presented in tables ( $n$ $=$ No. of tubules). Differences between means were evaluated using the paired $t$ test, with a $P$ value $<0.05$ considered statistically significant.

\section{Results}

Effect of vasopressin on bicarbonate absorption. The effects of AVP on bicarbonate transport by the medullary thick ascending limb are shown in Table I (mean values) and Fig. 1 (individual data). Vasopressin $\left(2.8 \times 10^{-10} \mathrm{M}\right)$ added to the bath reduced net bicarbonate absorption from 7.8 to $3.7 \mathrm{pmol} / \mathrm{min}$ per $\mathrm{mm}$ (Table I). The inhibition of bicarbonate absorption

3. In this paper, as in previous papers $(1,3,17)$, total $\mathrm{CO}_{2}$ absorption is referred to generally as bicarbonate absorption and total ammonia absorption is referred to as ammonium absorption. When mechanisms of ammonium transport are discussed, the chemical formulae $\mathrm{NH}_{4}^{+}$ and $\mathrm{NH}_{3}$ are used to indicate the particular species transported. 


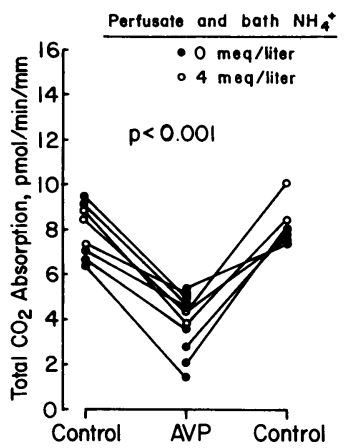

Figure 1. Effect of AVP $\left(2.8 \times 10^{-10}\right.$ $\mathrm{M}$ in the bath) on total $\mathrm{CO}_{2}$ absorption by the rat medullary thick ascending limb. Solid and open circles are mean values for single tubules: lines connect paired measurements made in the same tubule. $P$ value is for paired $t$ test.

was reversible (Fig. 1) and could be observed within 10-15 min after addition of vasopressin to the bath. Vasopressin caused a small but significant increase in the transepithelial voltage (Table I). In three additional tubules studied with $4 \mathrm{mM}$ $\mathrm{NH}_{4} \mathrm{Cl}$ in the perfusate and bath, vasopressin $\left(2.8 \times 10^{-10} \mathrm{M}\right.$ in the bath) reduced bicarbonate absorption rate from $8.3 \pm 0.5$ to $4.9 \pm 0.6 \mathrm{pmol} / \mathrm{min}$ per $\mathrm{mm}$ (open circles, Fig. 1).

Effect of vasopressin on bicarbonate absorption in the presence of furosemide. To determine whether the inhibition of bicarbonate absorption may have been the indirect result of an effect of vasopressin on transcellular $\mathrm{NaCl}$ transport, the effect of vasopressin was studied in tubules perfused with furosemide to inhibit net $\mathrm{NaCl}$ absorption (Table II, Fig. 2). With $10^{-4} \mathrm{M}$ furosemide in the luminal perfusate, vasopressin $\left(2.8 \times 10^{-10}\right.$ $\mathrm{M}$ in the bath) reduced net $\mathrm{HCO}_{3}^{-}$absorption from 11.5 to 8.1 $\mathrm{pmol} / \mathrm{min}$ per $\mathrm{mm}$ (Table II). The inhibition was reversed when vasopressin was removed from the bathing solution (Fig. 2). Thus, the effect of vasopressin to inhibit $\mathrm{HCO}_{3}^{-}$absorption was similar in the presence and absence of furosemide. With furosemide, the transepithelial voltage was near zero and was unaffected by vasopressin (Table II).

Effect of Glu on bicarbonate absorption. The effects of Glu are shown in Table III and Fig. 3. Glu $\left(2 \times 10^{-9} \mathrm{M}\right)$ added to the bath reduced net bicarbonate absorption from 11.7 to 7.6 $\mathrm{pmol} / \mathrm{min}$ per $\mathrm{mm}$ (Table III). This effect was reversible (Fig. 3 ). Glu increased the transepithelial voltage in four of five tubules; however, the net increase in voltage was small and was of borderline significance $(0.05<P<0.1)$.

Table II. Effect of AVP on Bicarbonate Transport (10-4 M Luminal Furosemide)

\begin{tabular}{lccccc}
\hline & & \multicolumn{2}{c}{$\left[\right.$ Total $\left.\mathrm{CO}_{2}\right]$} & & \\
\cline { 3 - 4 } & $V$ & Perfused & Collected & $J T \mathrm{CO}_{2}$ & $V_{\mathrm{TE}}$ \\
\hline & $n l / m i n$ & & $m M$ & $\begin{array}{c}\text { pmol/min } \\
\text { per } \mathrm{mm}\end{array}$ & $\mathrm{mV}$ \\
& & & & & \\
Control & $1.1 \pm 0.1$ & $25.4 \pm 0.2$ & $15.1 \pm 0.8^{*}$ & $11.5 \pm 1.0$ & $1.5 \pm 0.2$ \\
Vasopressin & $1.1 \pm 0.1$ & $25.4 \pm 0.2$ & $18.0 \pm 1.1^{*}$ & $8.1 \pm 1.2$ & $1.3 \pm 0.1$ \\
$P$ & $\mathrm{NS}$ & & $<0.005$ & $<0.005$ & $\mathrm{NS}$
\end{tabular}

Values are means \pm SE. Vasopressin was $2.8 \times 10^{-10} \mathrm{M}$ in the bath. In both control and vasopressin conditions, the luminal perfusate contained $1 \times 10^{-4} \mathrm{M}$ furosemide. No. of experiments $=5$. Mean tubule length $=0.49 \pm 0.03 \mathrm{~mm}$. Total $\mathrm{CO}_{2}$ concentration in the bath was $25.7 \pm 0.4 \mathrm{mM}$ in control and $25.9 \pm 0.5 \mathrm{mM}$ with vasopressin. $V$, $J \mathrm{TCO}_{2}, V_{\mathrm{TE}}, P$ values, and ${ }^{*}$ as in Table $\mathrm{I}$.

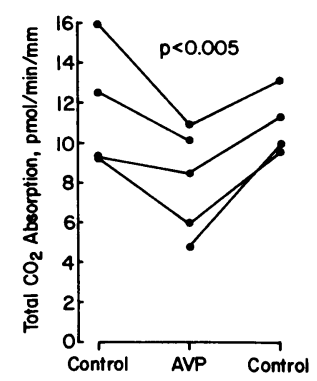

Figure 2. Effect of AVP $\left(2.8 \times 10^{-10} \mathrm{M}\right.$ in the bath) on total $\mathrm{CO}_{2}$ absorption in the presence of furosemide. Furosemide $\left(1 \times 10^{-4} \mathrm{M}\right)$ was present in the luminal perfusate throughout the experiments. Solid circles, lines, and $P$ value as in Fig. 1.

Effect of PTH on bicarbonate absorption. PTH $\left(2 \times 10^{-9}\right.$ or $3 \times 10^{-8} \mathrm{M}$ ) added to the bath caused a small but significant decrease in net bicarbonate absorption (Table IV, Fig. 4). The inhibition of bicarbonate absorption was reversible (Fig. 4) but was smaller in magnitude (19\%) than that observed with vasopressin or Glu (35-50\%, Tables I and III). PTH had no significant effect on transepithelial voltage (Table IV).

Effects of 8-bromo-cAMP and forskolin on bicarbonate absorption. To determine whether vasopressin and Glu may have inhibited bicarbonate absorption via their action to stimulate intracellular production of cAMP, the effects of exogenous 8-bromo-cAMP and forskolin (an agent that increases cell cAMP production) were examined in the absence of added hormone. 8-Bromo-cAMP $\left(1 \times 10^{-3} \mathrm{M}\right.$ in the bath $)$ reduced net bicarbonate absorption by $37 \%$, from 13.1 to $8.2 \mathrm{pmol} /$ min per mm (Table V, Fig. 5). Forskolin $\left(1 \times 10^{-6} \mathrm{M}\right.$ in the bath) reduced bicarbonate absorption by $30 \%$, from 16.7 to 12 $\mathrm{pmol} / \mathrm{min}$ per $\mathrm{mm}$ (Table V, Fig. 6). The effect of both agents to inhibit bicarbonate absorption was reversible (Figs. 5 and 6). Both 8-bromo-cAMP and forskolin significantly increased the transepithelial voltage (Table V).

Effect of vasopressin on bicarbonate absorption in the presence of 8-bromo-cAMP. To examine further whether cAMP may be responsible for the transport effects observed with vasopressin, the effects of vasopressin were studied in the presence of exogenous 8-bromo-cAMP. With 8-bromo-cAMP (1 $\left.\times 10^{-3} \mathrm{M}\right)$ in the bath, adding vasopressin $\left(2.8 \times 10^{-10} \mathrm{M}\right)$ to the bath had no significant effect on bicarbonate absorption (Table VI, Fig. 7). In the presence of 8-bromo-cAMP, vasopressin also had no significant effect on transepithelial voltage (Table VI).

Effect of vasopressin on ammonium absorption. The effect of AVP on ammonium transport by the medullary thick as-

Table III. Effect of Glu on Bicarbonate Transport

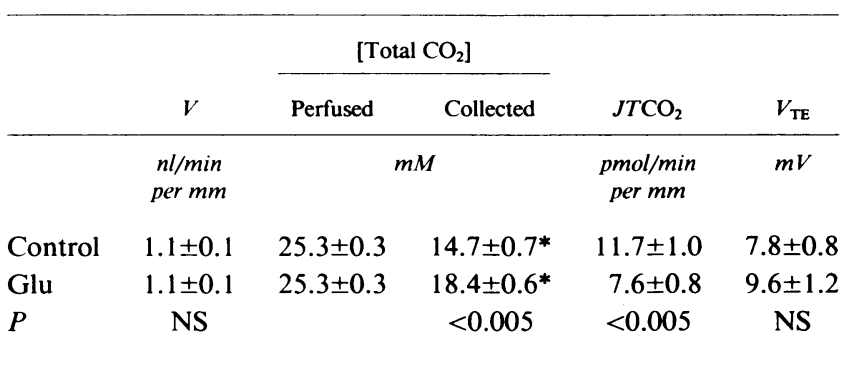

Values are means \pm SE. Glu was $2 \times 10^{-9} \mathrm{M}$ in the bath. No. of experiments $=5$. Mean tubule length $=0.56 \pm 0.03 \mathrm{~mm}$. Total $\mathrm{CO}_{2}$ concentration in the bath was $25.4 \pm 0.4 \mathrm{mM}$ in control and $25.4 \pm 0.4$ $\mathrm{mM}$ with Glu. $V, J T \mathrm{CO}_{2}, V_{\mathrm{TE}}, P$ values, and ${ }^{*}$ as in Table $\mathrm{I}$. 


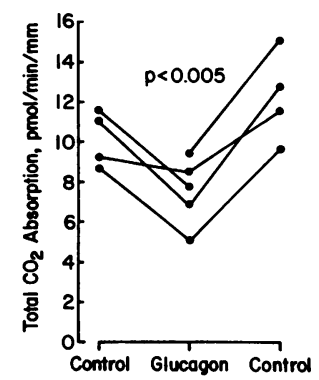

Figure 3. Effect of Glu $\left(2 \times 10^{-9} \mathrm{M}\right.$ in the bath) on total $\mathrm{CO}_{2}$ absorption by the rat medullary thick ascending limb. Solid circles, lines, and $P$ value as in Fig. 1. cending limb is shown in Table VII and Fig. 8. Vasopressin $\left(2.8 \times 10^{-10} \mathrm{M}\right)$ added to the bath did not significantly affect net ammonium absorption. To determine whether exposure times longer than those used in the bicarbonate transport experiments were required to observe an effect of vasopressin on ammonium absorption, tubules in some of the experiments were exposed to bath vasopressin for up to $100 \mathrm{~min}$ after an initial 60-90-min control period. Even with these prolonged time periods, no effect of vasopressin on ammonium absorption was observed.

\section{Discussion}

Peptide hormones such as vasopressin and PTH influence urinary net acid excretion and have been shown to alter luminal acidification in the proximal tubule, distal tubule, and cortical and inner medullary collecting ducts $(9-15,22-26)$. The present experiments were designed to determine directly whether peptide hormones affect bicarbonate absorption in the medullary thick ascending limb of the rat. The results show that vasopressin, Glu, and PTH inhibit bicarbonate absorption, and that this inhibition can be reproduced by procedures that increase intracellular levels of cAMP. Thus, peptide hormones and factors that regulate intracellular cAMP are likely to be important determinants of luminal acidification in the medullary thick ascending limb.

Effects of vasopressin on bicarbonate transport. Bicarbonate absorption was markedly inhibited by $2.8 \times 10^{-10} \mathrm{M}$ vasopressin (Fig. 1). This hormone concentration was used because it represents the upper end of the physiologic range of vasopressin concentrations, and because it had been shown pre-

Table IV. Effect of PTH on Bicarbonate Transport

\begin{tabular}{|c|c|c|c|c|c|}
\hline & \multirow[b]{2}{*}{$V$} & \multicolumn{2}{|c|}{ [Total $\mathrm{CO}_{2}$ ] } & \multirow[b]{2}{*}{$\mathrm{JTCO}_{2}$} & \multirow[b]{2}{*}{$V_{\mathrm{TE}}$} \\
\hline & & Perfused & Collected & & \\
\hline & $\begin{array}{l}\mathrm{nl} / \mathrm{min} \\
\mathrm{per} \mathrm{mm}\end{array}$ & \multicolumn{2}{|c|}{$m M$} & $\begin{array}{c}\text { pmol/min } \\
\text { per mm }\end{array}$ & $m V$ \\
\hline Control & $1.1 \pm 0.1$ & $25.2 \pm 0.4$ & $14.4 \pm 0.8^{*}$ & $12.5 \pm 0.8$ & $9.4 \pm 1.1$ \\
\hline PTH & $1.2 \pm 0.1$ & $25.2 \pm 0.4$ & $16.6 \pm 0.7^{*}$ & $10.1 \pm 0.7$ & $10.0 \pm 0.5$ \\
\hline$P$ & NS & & $<0.001$ & $<0.005$ & NS \\
\hline
\end{tabular}

Values are means \pm SE and are combined results of experiments with $2 \times 10^{-9}$ and $3 \times 10^{-8} \mathrm{M}$ PTH in the bath. Total no. of experiments $=8\left(n=5\right.$ with $2 \times 10^{-9} \mathrm{M}$ PTH; $n=3$ with $\left.3 \times 10^{-8} \mathrm{M} \mathrm{PTH}\right)$. Mean tubule length $=0.50 \pm 0.03 \mathrm{~mm}$. Total $\mathrm{CO}_{2}$ concentration in bath was $25.5 \pm 0.2 \mathrm{mM}$ in control and $25.6 \pm 0.4 \mathrm{mM}$ with PTH. $V$, $J \mathrm{JCO}_{2}, V_{\mathrm{TE}}, P$ values, and ${ }^{*}$ as in Table $\mathrm{I}$.

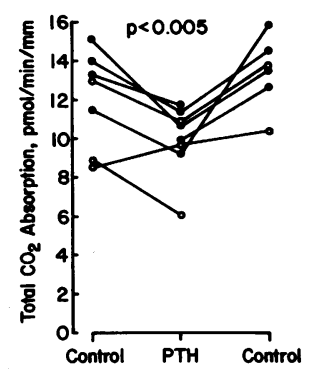

Figure 4. Effect of PTH in the bath on total $\mathrm{CO}_{2}$ absorption by the rat medullary thick ascending limb. Solid circles, 2 $\times 10^{-9} \mathrm{M}$ PTH; open circles, $3 \times 10^{-8} \mathrm{M}$ PTH. Lines and $P$ value as in Fig. 1.

viously to stimulate net $\mathrm{NaCl}$ absorption in the isolated, perfused rat medullary thick ascending limb (21). The inhibition of bicarbonate absorption was observed with or without $\mathrm{NH}_{4} \mathrm{Cl}$ in the perfusate and bath, and was sustained for as long as vasopressin was present in the bathing solution.

The direct inhibition of bicarbonate absorption in the medullary thick ascending limb in vitro can explain, in part, the recent observation that an acute infusion of 1-deamino-8-DAVP decreased fractional bicarbonate reabsorption in the loop segment of the Sprague-Dawley rat in vivo (12). The inhibition in vivo was observed in hormone-deprived rats in which the potential effects of endogenous peptide hormones were minimized by hypotonic volume expansion, thyroparathyroidectomy, and somatostatin infusion, but could not be detected in intact rats that received only hypotonic volume expansion (12). These findings suggest that factors other than vasopressin influence loop segment bicarbonate transport; however, they do not preclude an important regulatory role for the action of vasopressin on the medullary thick ascending limb for several reasons: $(a)$ the medullary thick ascending limb may be relatively short in superficial nephrons, minimizing the impact of vasopressin on overall loop bicarbonate transport; $(b)$ changes in bicarbonate absorption in the cortical thick ascending limb may compensate for changes in the medullary segment (see below); and (c) direct effects of vasopressin on the medullary thick ascending limb may be opposed by other luminal or systemic factors that change with vasopressin and that indirectly influence loop bicarbonate transport.

In contrast to its action to inhibit bicarbonate absorption in the medullary thick ascending limb, vasopressin stimulates net bicarbonate absorption in the distal tubule and collecting ducts $(12,25,26)$ and increases urinary net acid excretion (11, 12). The physiologic importance of increased net acid excretion with vasopressin may be to maintain plasma $\mathrm{pH}$ during states of antidiuresis when water retention would tend to dilute the plasma bicarbonate concentration (12). A possible means by which the thick ascending limb could contribute to the vasopressin-related stimulation of urine acidification would be as follows. If vasopressin inhibited bicarbonate absorption in the medullary thick ascending limb but not in the cortical thick ascending limb (as is the case for vasopressin stimulation of $\mathrm{NaCl}$ absorption [6]), then an increase in bicarbonate absorption by the cortical segment, in response to the increased bicarbonate load, could compensate for the decrease in absorption in the medullary segment. The net result would be a shift in bicarbonate absorption from the medullary to the cortical thick ascending limb with little or no change in overall loop bicarbonate transport. This would have the important effect of reducing net bicarbonate delivery to the medullary interstitium, which could limit the bicarbonate concentration 


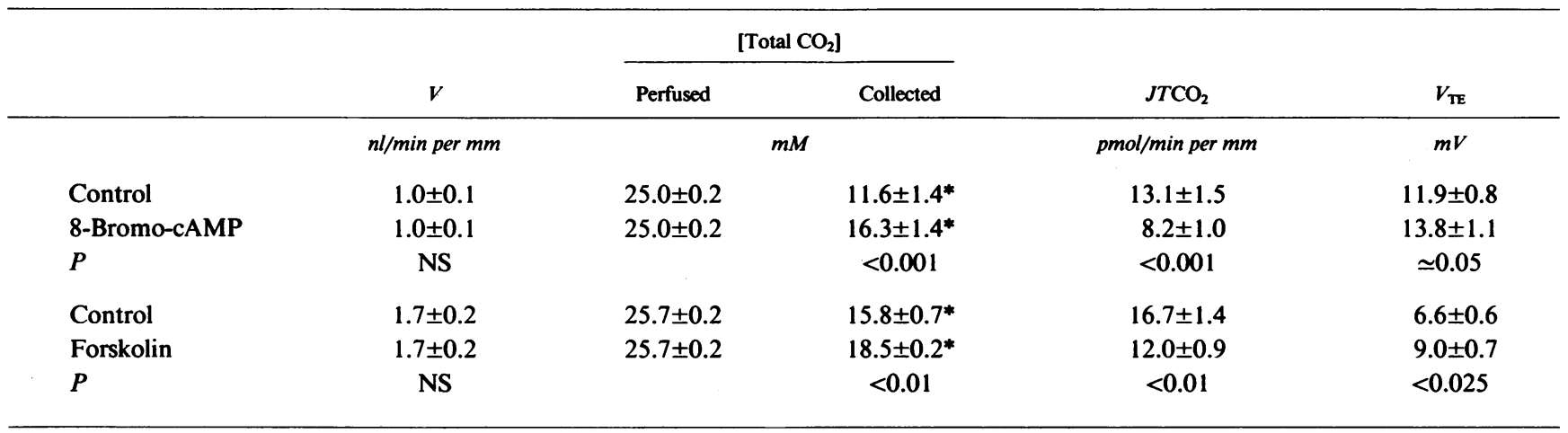

Values are means \pm SE. 8-Bromo-cAMP was $1 \times 10^{-3} \mathrm{M}$ and forskolin was $1 \times 10^{-6} \mathrm{M}$ in the bath. No. of experiments $=8$ with 8-bromocAMP and 5 with forskolin. Mean tubule length was $0.57 \pm 0.03 \mathrm{~mm}$ with 8 -bromo-cAMP and $0.46 \pm 0.05 \mathrm{~mm}$ with forskolin. Total $\mathrm{CO}_{2}$ concentration in bath was $25.4 \pm 0.2 \mathrm{mM}$ in control, $25.5 \pm 0.1 \mathrm{mM}$ with 8 -bromo-cAMP, and $25.9 \pm 0.3 \mathrm{mM}$ with forskolin. $V, J T C O_{2}, V_{\mathrm{TE}}, P$ values, and * as in Table I.

surrounding the medullary collecting ducts and enhance collecting duct proton secretion. Such an effect may be particularly important with vasopressin, since concentrations of medullary solutes are greatest during antidiuresis. Further studies of the effects of vasopressin on the cortical thick ascending limb and on medullary acid-base handling will be required to evaluate this hypothesis.

Mechanisms of vasopressin action. The effect of vasopressin to inhibit bicarbonate absorption can be accounted for by its action to stimulate adenylyl cyclase and increase the intracellular production of cAMP. This view is supported by several observations: $(a)$ vasopressin in physiologic concentrations $\left(10^{-11}-10^{-10} \mathrm{M}\right)$ stimulates adenylyl cyclase and increases cAMP production in the rat medullary thick ascending limb $(4,8,27) ;(b)$ an analogue of cAMP (8-bromo-cAMP) closely mimicked vasopressin action (Fig. 5); (c) the effect of vasopressin to inhibit bicarbonate absorption was blocked by exogenous 8-bromo-cAMP (Fig. 7); (d) forskolin, an agent that stimulates intracellular cAMP production $(28,29)$, inhibited bicarbonate absorption (Fig. 6); and (e) Glu, another hormone that stimulates adenylyl cyclase activity in medullary thick ascending limbs $(4,7,8)$, inhibited bicarbonate absorption by an amount similar to that observed with vasopressin (Fig. 3).

One possible explanation for the inhibition of bicarbonate absorption would be that it occurs as an indirect result of the effect of vasopressin to stimulate net $\mathrm{NaCl}$ absorption. Vaso- pressin (via cAMP) increases net $\mathrm{NaCl}$ absorption in mouse (6, 20) and rat (21) medullary thick ascending limbs and this effect is associated with increased apical sodium uptake via the $\mathrm{Na}^{+}-\mathrm{K}^{+}-2 \mathrm{Cl}^{-}$cotransport system $(6,30)$. The vasopressin-dependent increase in $\mathrm{Na}^{+}$uptake could increase cell $\mathrm{Na}^{+}$activity, reduce the $\mathrm{Na}^{+}$gradient driving apical membrane $\mathrm{Na}^{+}-\mathrm{H}^{+}$ exchange, and inhibit net bicarbonate absorption. To test this possibility, the effect of vasopressin was examined in tubules perfused with furosemide to inhibit $\mathrm{Na}^{+}-\mathrm{K}^{+}-2 \mathrm{Cl}^{-}$cotransport and transcellular $\mathrm{NaCl}$ absorption (5). The results show that vasopressin inhibited bicarbonate absorption to a similar extent either in the presence or absence of luminal furosemide. Thus, the inhibition of bicarbonate absorption occurs independent of effects on net $\mathrm{NaCl}$ absorption. The experiments with furosemide also demonstrate that the inhibition of bicarbonate absorption can occur in the absence of a change in transepithelial voltage (Table II).

Another means by which vasopressin and cAMP could inhibit bicarbonate absorption would be by inhibiting apical membrane $\mathrm{Na}^{+}-\mathrm{H}^{+}$exchange, which mediates most of transcellular bicarbonate absorption in the rat thick ascending limb $(2,3)$. cAMP and hormones such as PTH that stimulate production of cAMP, have been shown to inhibit $\mathrm{Na}^{+}-\mathrm{H}^{+}$exchange and net bicarbonate absorption in proximal tubules $(9$, $22,23,31$ ) and in renal brush border membranes (32). cAMP also inhibits $\mathrm{Na}^{+}-\mathrm{H}^{+}$exchange in the apical membrane of the

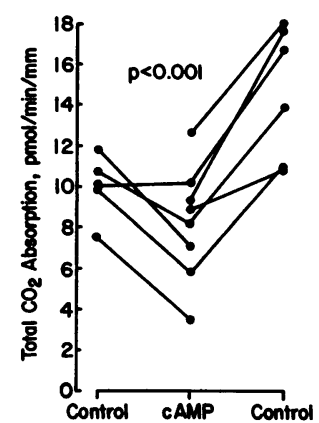

Figure 5. Effect of 8-bromo-cAMP (cAMP; $1 \times 10^{-3} \mathrm{M}$ in the bath) on total $\mathrm{CO}_{2}$ absorption by the rat medullary thick ascending limb. Solid circles, lines, and $P$ value as in Fig. 1.

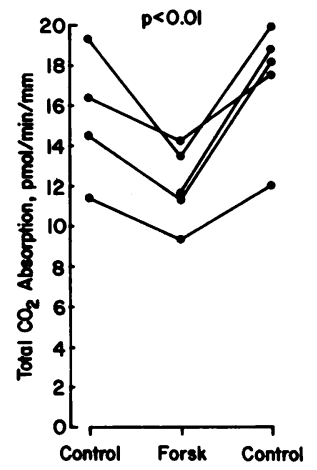

Figure 6. Effect of forskolin (Forsk; 1 $\times 10^{-6} \mathrm{M}$ in the bath) on total $\mathrm{CO}_{2} \mathrm{ab}$ sorption by the rat medullary thick ascending limb. Solid circles, lines, and $P$ value as in Fig. 1. 


\begin{tabular}{|c|c|c|c|c|c|}
\hline & \multirow[b]{2}{*}{$\boldsymbol{V}$} & \multicolumn{2}{|c|}{ [Total $\mathrm{CO}_{2}$ ] } & \multirow[b]{2}{*}{$\mathrm{JTCO}_{2}$} & \multirow[b]{2}{*}{$V_{T E}$} \\
\hline & & Perfused & Collected & & \\
\hline & $\mathrm{nl} / \mathrm{min}$ per $\mathrm{mm}$ & & & $\mathrm{pmol} / \mathrm{min}$ per $\mathrm{mm}$ & $m V$ \\
\hline 8-Bromo-cAMP & $1.2 \pm 0.1$ & $25.4 \pm 0.3$ & $19.1 \pm 0.7^{*}$ & $7.3 \pm 0.4$ & $9.5 \pm 1.0$ \\
\hline Vasopressin + 8-bromo-cAMP & $1.2 \pm 0.1$ & $25.4 \pm 0.3$ & $19.3 \pm 0.5^{*}$ & $6.9 \pm 0.5$ & $8.8 \pm 1.1$ \\
\hline$P$ & NS & & NS & NS & NS \\
\hline
\end{tabular}

Values are means \pm SE. Vasopressin was $2.8 \times 10^{-10} \mathrm{M}$ in the bath. The bath contained $1 \times 10^{-3} \mathrm{M}$ 8-bromo-cAMP throughout the experiments. No. of experiments $=7$. Mean tubule length $=0.58 \pm 0.02 \mathrm{~mm}$. Bath total $\mathrm{CO}_{2}$ concentration was $26.2 \pm 0.5 \mathrm{mM}$ in both $8-\mathrm{Bromo}-$ cAMP and vasopressin + 8-bromo-cAMP conditions. $V, J T \mathrm{JO}_{2}, V_{\mathrm{TE}}, P$ values, and ${ }^{*}$ as in Table $\mathrm{I}$.

Necturus gallbladder (33). However, whether cAMP inhibits apical $\mathrm{Na}^{+}-\mathrm{H}^{+}$exchange in the medullary thick ascending limb has not been determined.

Effects of Glu on bicarbonate transport. Glu directly inhibited bicarbonate absorption (Fig. 3). As discussed above, this effect can best be accounted for by the action of Glu to stimulate adenylyl cyclase and increase intracellular production of cAMP (4). The similarity of the effects of Glu and vasopressin on bicarbonate absorption in the medullary thick ascending limb supports the concept of multiple hormonal control in which different hormones that activate adenylyl cyclase in a particular nephron segment are predicted to exert a similar physiologic effect $(4,7)$.

In recent studies in hormone-deprived rats, the acute infusion of Glu to physiologic levels caused an increase in urinary bicarbonate excretion and a decrease in net acid excretion (13). The increase in bicarbonate excretion was associated with a decrease in fractional bicarbonate absorption by the loop segment $(10,15)$. Results of the present study indicate that this decrease can be explained, at least in part, by direct inhibition of bicarbonate absorption in the medullary thick ascending limb. At the present time the physiological importance of the effects of Glu on urinary acidification is unknown.

Effects of PTH on bicarbonate transport. Bichara et al. reported recently that infusion of PTH into thyroparathyroidectomized rats increased bicarbonate absorption along the superficial loop segment (14). Results of the present study show, however, that PTH directly inhibited bicarbonate absorption in the medullary thick ascending limb (Fig. 4). Furthermore, preliminary studies in this laboratory have shown that PTH also inhibits bicarbonate absorption in the rat cortical thick ascending limb (Good, D., unpublished observations). ${ }^{4}$ Thus, the increase in loop bicarbonate absorption seen with PTH administration in vivo does not appear to be due to direct hormonal stimulation of bicarbonate absorption in the thick ascending limb. Because the extent of inhibition of bicarbonate absorption by PTH in vitro was relatively small $(<20 \%)$, and because the effect was observed using PTH concentrations above the physiological range, it is uncertain whether inhibition of bicarbonate absorption in the medullary thick ascending limb represents an important physiologic effect of the hor-

4. In two experiments with cortical thick ascending limbs, bicarbonate absorption rate with $3 \times 10^{-8} \mathrm{M}$ PTH in the bath was $1-3 \mathrm{pmol} / \mathrm{min}$ per $\mathrm{mm}$ compared with $7-9 \mathrm{pmol} / \mathrm{min}$ per $\mathrm{mm}$ measured in controls. mone. If PTH does not significantly inhibit thick ascending limb bicarbonate absorption in vivo, then the stimulation of loop bicarbonate absorption observed after PTH infusion (14) may simply reflect the ability of the loop segment to increase its bicarbonate absorptive capacity in response to the increase in bicarbonate load (increase in luminal bicarbonate concentration) delivered to it from the proximal tubule.

The mechanisms by which PTH affects bicarbonate transport in the medullary thick ascending limb are uncertain. PTH inhibits bicarbonate absorption and $\mathrm{Na}^{+}-\mathrm{H}^{+}$exchange in cells of the proximal tubule, and these actions are mimicked by analogues of cAMP $(9,22,23,31,32)$. Several studies, however, have reported no effect of PTH on adenylyl cyclase activity in the medullary thick ascending limb (34-36). It is possible, however, that the sensitivity of the adenylyl cyclase assay may be insufficient, or that performance of the assay in lysed cells under nonphysiological conditions may be inadequate to detect modest $(\sim 50 \%)$ changes in cyclase activity that may occur in intact cells and be physiologically significant. Alternatively, PTH could influence bicarbonate transport in thick ascending limbs by other mechanisms such as activation of $\mathrm{Ca}^{2+}$-dependent messenger systems $(37,38)$, effects on prostaglandins, or inhibition of carbonic anhydrase (39).

Effect of vasopressin on ammonium transport. In addition to reabsorbing bicarbonate, a second means by which the thick ascending limb influences urinary net acid excretion is by reabsorbing ammonium $(1,18)$. Absorption of $\mathrm{NH}_{4}^{+}$by the medullary thick ascending limb enhances urinary ammonium excretion by promoting countercurrent multiplication of ammonium in the renal medulla, which facilitates secretion of ammonium into the collecting ducts (16-18). Absorption of ammonium by the medullary thick ascending limb occurs predominantly by secondary active transport, mediated by sub-

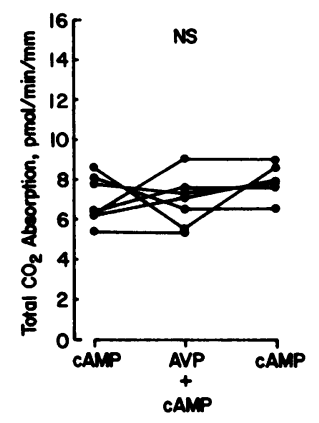

Figure 7. Effect of AVP $\left(2.8 \times 10^{-10} \mathrm{M}\right.$ in the bath) on total $\mathrm{CO}_{2}$ absorption in the presence of 8-bromo-cAMP. 8Bromo-cAMP $\left(1 \times 10^{-3} \mathrm{M}\right)$ was present in the bath throughout the experiments. Solid circles and lines as in Fig. 1. NS, No significant difference (paired $t$ test). 
Table VII. Effect of AVP on Ammonium Transport

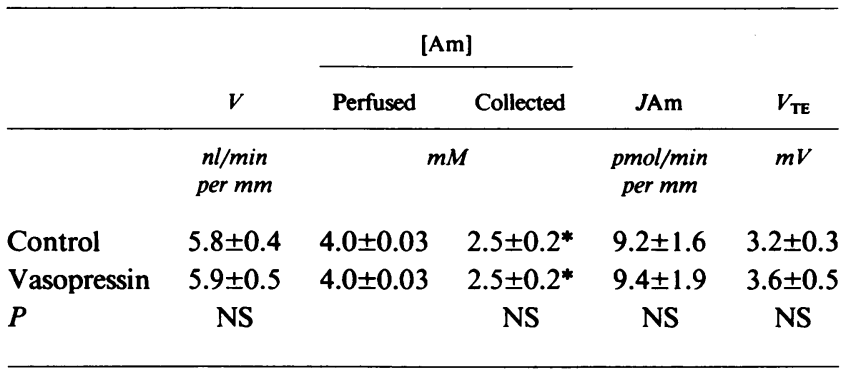

Values are means \pm SE. Vasopressin was $2.8 \times 10^{-10} \mathrm{M}$ in the bath. No. of experiments $=6$. Mean tubule length $=0.56 \pm 0.02 \mathrm{~mm}$. $[\mathrm{Am}]$ is total ammonia concentration; JAm is absolute rate of total ammonia absorption. Total ammonia concentration in bath was $4.0 \pm 0.1$ $\mathrm{mM}$ in both control and vasopressin conditions. $V$ and $V_{\mathrm{TE}}$ are as in Table I. $P$ values compare control and vasopressin (paired $t$ test). * Collected total ammonia concentration significantly different from perfused (paired $t$ test).

stitution of $\mathrm{NH}_{4}^{+}$for $\mathrm{K}^{+}$on the apical membrane $\mathrm{Na}^{+}-\mathrm{K}^{+}-2 \mathrm{Cl}^{-}$ cotransport system $(1,40-42)$. The previous observation that vasopressin stimulates apical $\mathrm{Na}^{+}-\mathrm{K}^{+}-2 \mathrm{Cl}^{-}$uptake in mouse and rat medullary thick ascending limbs $(6,21,30)$ suggested that $\mathrm{NH}_{4}^{+}$uptake via the cotransporter also might be accelerated. The results show, however, that vasopressin had no significant effect on net ammonium absorption (Table VII, Fig. 8). Therefore, vasopressin either did not stimulate apical $\mathrm{NH}_{4}^{+}$ uptake, or an increase in $\mathrm{NH}_{4}^{+}$uptake was offset by another effect tending to reduce net $\mathrm{NH}_{4}^{+}$absorption.

The observation that vasopressin markedly inhibits net bicarbonate absorption with no effect on net ammonium absorption illustrates that ammonium and bicarbonate transport rates can be regulated independently in the thick ascending limb. In the medullary thick ascending limb, net ammonium absorption is due to direct $\mathrm{NH}_{4}^{+}$transport that is predominantly transcellular and active $(40,41)$. Furthermore, backdiffusion of $\mathrm{NH}_{3}$ from bath to lumen, which could be influenced by luminal $\mathrm{pH}$, comprises only a small fraction of the net ammonium flux due to the low $\mathrm{NH}_{3}$ concentrations at physiological $\mathrm{pH}$ and to a relatively low transepithelial $\mathrm{NH}_{3}$ permeability $(17,41) .^{5}$ Thus, it is not surprising that $\mathrm{NH}_{4}^{+}$ absorption in the medullary thick ascending limb might be relatively insensitive to changes in luminal $\mathrm{pH}$. The observations that changes in potassium concentration inhibited net $\mathrm{NH}_{4}^{+}$absorption with no effect on bicarbonate absorption (18, 40 ) and that furosemide inhibited $\mathrm{NH}_{4}^{+}$absorption while stimulating net bicarbonate absorption $(1,3)$ illustrate further that $\mathrm{NH}_{4}^{+}$and $\mathrm{HCO}_{3}^{-}$transport rates can vary independently in thick ascending limbs.

5. Using the collected fluid bicarbonate and ammonium concentrations in Tables I and VII, and assuming a transepithelial $\mathrm{NH}_{3}$ permeability of $3 \times 10^{-3} \mathrm{~cm} / \mathrm{s}(41)$, the calculated change in $\mathrm{NH}_{3}$ backflux with vasopressin would be $\sim 0.9 \mathrm{pmol} / \mathrm{min}$ per $\mathrm{mm}$. This represents an upper estimate since high flow rates used in the ammonium transport experiments would tend to minimize luminal $\mathrm{pH}$ changes. Thus, the change in $\mathrm{NH}_{3}$ backflux would be $<10 \%$ of the net ammonium absorptive flux.



\section{Acknowledgments}

The author thanks Dr. Thomas D. DuBose, Jr. for his continued support and for careful review of the manuscript. Excellent technical assistance was provided by Jose Molina. The assistance of Ofilia Chlamon in preparation of the manuscript also is appreciated.

This research was supported by National Institute of Diabetes and Digestive and Kidney Diseases (NIDDK) grant DK-38217. D. Good is the recipient of an NIDDK Research Career Development Award (DK-01745).

\section{References}

1. Good, D. W., M. A. Knepper, and M. B. Burg. 1984. Ammonia and bicarbonate transport by thick ascending limb of rat kidney. Am. J. Physiol. 247 (Renal Fluid Electrolyte Physiol. 16):F35-F44.

2. Good, D. W. 1990. Bicarbonate absorption by the thick ascending limb of Henle's loop. Semin. Nephrol. In press.

3. Good, D. W. 1985. Sodium-dependent bicarbonate absorption by cortical thick ascending limb of rat kidney. Am. J. Physiol. 248 (Renal Fluid Electrolyte Physiol. 17):F821-F829.

4. Morel, F., and A. Doucet. 1986. Hormonal control of kidney functions at the cell level. Physiol. Rev. 66:377-468.

5. Greger, R. 1985. Ion transport mechanisms in thick ascending limb of Henle's loop of mammalian nephron. Physiol. Rev. 65:760797.

6. Hebert, S. C., W. B. Reeves, D. A. Molony, and T. E. Andreoli. 1987. The medullary thick ascending limb: function and modulation of the single-effect multiplier. Kidney Int. 31:580-588.

7. DeRouffignac, C., J. Elalouf, and N. Roinel. 1987. Physiological control of the urinary concentrating mechanism by peptide hormones. Kidney Int. 31:611-620.

8. Morel, F., M. Imbert-Teboul, and D. Chabardes. 1987. Receptors to vasopressin and other hormones in the mammalian kidney. Kidney Int. 31:512-520.

9. Hulter, H. N. 1985. Effects and interrelationships of $\mathrm{PTH}, \mathrm{Ca}^{2+}$, vitamin $\mathrm{D}$, and $\mathrm{P}_{\mathrm{i}}$ in acid-base homeostasis. Am. J. Physiol. 248:F739-F752.

10. Paillard, M., M. Bichara, O. Mercier, F. Leviel, M. Delahousse, and A. Prigent. 1988. Bicarbonate and chloride absorption in Henle's loop and the role of peptide hormones. In Nephrology. Vol. I. A. M. Davison, editor. Bailliere Tindall, London. 275-280.

11. Lowance, D. C., H. B. Garfinkel, W. D. Mattern, and W. B. Schwartz. 1972. The effect of chronic hypotonic volume expansion on the renal regulation of acid-base equilibrium. J. Clin. Invest. 51:29282940.

12. Bichara, M., O. Mercier, P. Houillier, M. Paillard, and F. Leviel. 1987. Effects of antidiuretic hormone on urinary acidification and on tubular handling of bicarbonate in the rat. J. Clin. Invest. 80:621630 . 
13. Delahousse, M., O. Mercier, M. Bichara, M. Paillard, F. Leviel, and R. Assan. 1988. Glucagon inhibits urinary acidification in the rat. Am. J. Physiol. 254:F762-F769.

14. Bichara, M., O. Mercier, M. Paillard, and F. Leviel. 1986. Effects of parathyroid hormone on urinary acidification. Am. J. Physiol. 251:F444-F453.

15. Mercier, O., M. Bichara, M. Delahousse, A. Prigent, F. Leviel, and $\mathrm{M}$. Paillard 1989. Effects of glucagon on $\mathrm{H}^{+}-\mathrm{HCO}_{3}{ }^{-}$transport in Henle's loop, distal tubule, and collecting ducts in the rat. Am. J. Physiol. 257 (Renal Fluid Electrolyte Physiol. 26):F1003-F1014.

16. Good, D. W., and M. A. Knepper. 1985. Ammonia transport in the mammalian kidney. Am. J. Physiol. 248 (Renal Fluid Electrolyte Physiol. 17):F459-F471.

17. Knepper, M. A., R. Packer, and D. W. Good. 1989. Ammonium transport in the kidney. Physiol. Rev. 69:179-249.

18. Good, D. W. 1987. Effects of potassium on ammonia transport by medullary thick ascending limb of the rat. J. Clin. Invest. 80:13581365.

19. Knepper, M. A. 1983. Urea transport in isolated, perfused thick ascending limbs and collecting ducts from rats. Am. J. Physiol. 245 (Renal Fluid Electrolyte Physiol. 14):F634-F639.

20. Sasaki, S., and M. Imai. 1980. Effects of vasopressin on water and $\mathrm{NaCl}$ transport across the in vitro perfused medullary thick ascending limb of Henle's loop of mouse, rat and rabbit kidneys. Pfleugers Arch. Eur. S. Physiol. 383:215-221.

21. Work, J., J. H. Galla, B. B. Booker, J. A. Schafer, and R. G. Luke. 1985. Effect of ADH on chloride reabsorption in the loop of Henle of the Brattleboro rat. Am. J. Physiol. 249 (Renal Fluid Electrolyte Physiol. 18):F698-F703.

22. lino, Y., and M. B. Burg. 1979. Effect of parathyroid hormone on bicarbonate absorption by proximal tubules in vitro. Am. J. Physiol. 236:F387-F391.

23. McKinney, T. D., and P. Myers. 1980. Bicarbonate transport by proximal tubules: effect of parathyroid hormone and dibutyryl cyclic AMP. Am. J. Physiol. 238:F166-F174.

24. Bengele, H. H., E. R. McNamara, and E. A. Alexander. 1984 Effect of acute thyroparathyroidectomy on nephron acidification. Am. J. Physiol. 246 (Renal Fluid Electrolyte Physiol. 15):F569-F574.

25. Tomita, K., J. J. Pisano, M. B. Burg, and M. A. Knepper. 1986. Effects of vasopressin and bradykinin on anion transport by the rat cortical collecting duct. Evidence for an electroneutral sodium chloride transport pathway. J. Clin. Invest. 77:136-141.

26. Wall, S. M., J. M. Sands, M. F. Flessner, H. Nonoguchi, K. R. Spring, and M. A. Knepper. 1990. Net acid transport by isolated perfused inner medullary collecting ducts. Am. J. Physiol. 258 (Renal Fluid Electrolyte Physiol. 27):F75-F84.

27. Imbert-Teboul, M., D. Chabardes, M. Montegut, A. Clique, and F. Morel. 1978. Vasopressin-dependent adenylate cyclase activities in the rat kidney medulla: evidence for two separate sites of action. Endocrinology. 102:1254-1261.
28. Seamon, K. B., and J. W. Daly. 1983. Forskolin, cyclic AMP, and cellular physiology. Trends Pharmacol. Sci. 4:120-123.

29. Culpepper, R. M., and T. E. Andreoli. 1984. $\mathrm{PGE}_{2}$, forskolin, and cholera toxin interactions in modulating $\mathrm{NaCl}$ transport in mouse mTAL. Am. J. Physiol. 247 (Renal Fluid Electrolyte Physiol. 16):F784-F792.

30. Molony, D. A., W. B. Reeves, S. C. Hebert, and T. E. Andreoli. 1987. ADH increases apical $\mathrm{Na}^{+}, \mathrm{K}^{+}, 2 \mathrm{Cl}^{+}$entry in mouse medullary thick ascending limbs of Henle. Am. J. Physiol. 252 (Renal Fluid Electrolyte Physiol. 21):F177-F187.

31. Pollock, A. S., D. G. Warnock, and G. J. Strewler. 1986. Parathyroid hormone inhibition of $\mathrm{Na}^{+}-\mathrm{H}^{+}$antiporter activity in cultured renal cell line. Am. J. Physiol. 250:F217-F225.

32. E. J. Weinman, S. Shenolikar, and A. M. Kahn. 1987. cAMPassociated inhibition of $\mathrm{Na}^{+}-\mathrm{H}^{+}$exchanger in rabbit kidney brushborder membranes. Am. J. Physiol. 252:F19-F25.

33. Reuss, L., and K.-U. Peterson. 1985. Cyclic AMP inhibits $\mathrm{Na}^{+} / \mathrm{H}^{+}$exchange at the apical membrane of Necturus gallbladder epithelium. J. Gen. Physiol. 85:409-429.

34. Torikai, S., M.-S. Wang, K. L. Klein, and K. Kurokawa. 1981. Adenylate cyclase and cell cyclic AMP of rat cortical thick ascending limb of Henle. Kidney Int. 20:649-654.

35. Imbert-Teboul, M., D. Chabardes, A. Clique, M. Montegut, and F. Morel. 1984. Ontogenesis of hormone-dependent adenylate cyclase in isolated rat nephron segments. Am. J. Physiol. 247:F316F325.

36. Trinh-Trang-Tan, M.-M., N. Bouby, C. Coutand, and L. Bankir. 1986. Quick isolation of rat medullary thick ascending limbs: enzymatic and metabolic characterization. Pfluegers Arch. Eur. J. Physiol. 407:228-234.

37. Troyer, D. A., D. W. Schwertz, J. I. Kreisberg, and M. A. Venkatachalam. 1986. Inositol phospholipid metabolism in the kidney. Annu. Rev. Physiol. 48:51-71.

38. Cole, J. A., S. L. Eber, R. E. Poelling, P. K. Thorne, and L. R. Forte. 1987. A dual mechanism for regulation of kidney phosphate transport by parathyroid hormone. Am. J. Physiol. 253 (Endocrinol. Metab. 16):E221-E227.

39. Beck, N., K. S. Kim, M. Wolak, and B. B. Davis. 1975. Inhibition of carbonic anhydrase by parathyroid hormone and cyclic AMP in rat renal cortex in vitro. J. Clin. Invest. 55:149-156.

40. Good, D. W. 1988. Active absorption of $\mathrm{NH}_{4}^{+}$by rat medullary thick ascending limb: inhibition by potassium. Am. J. Physiol. 255 (Renal Fluid Electrolyte Physiol. 24):F78-F87.

41. Garvin, J. L., M. B. Burg, and M. A. Knepper. 1988. Active $\mathrm{NH}_{4}^{+}$absorption by the thick ascending limb. Am. J. Physiol. 255 (Renal Fluid Electrolyte Physiol. 24):F57-F65.

42. Kinne, R., E. Kinne-Saffran, H. Schutz, and B. Scholermann. 1986. Ammonium transport in medullary thick ascending limb of rabbit kidney: involvement of the $\mathrm{Na}^{+}, \mathrm{K}^{+}, \mathrm{Cl}^{-}$cotransporter. $J$. Membr. Biol. 94:279-284. 